\title{
Prediction of Salt Tolerance in Rice (Oryza Sativa) Based on Shoot Ion Content under Non-Stressed Conditions
}

\author{
Souleymane Bado ${ }^{1 *}$, Brian Peter Forster ${ }^{1,2}$, Roman Padilla-Alvarez ${ }^{3}$, Christian Resch ${ }^{4}$, Alessandro Migliori ${ }^{3}$, \\ Yacouba Diawara ${ }^{3}$, Milko Jakšić ${ }^{5}$, Abdelbagi Mukhtar Ali Ghanim ${ }^{1}$, Stephen Nielen ${ }^{1}$ and Margit Laimer ${ }^{6}$ \\ 1. Plant Breeding and Genetics Laboratory (PBGL), Joint FAO/IAEA Division of Nuclear Techniques in Food and Agriculture, IAEA \\ Laboratories Seibersdorf, International Atomic Energy Agency, PO Box 100, Wagramerstrasse 5, A-1400 Vienna, Austria \\ 2. Current address: BioHybrids International Ltd, P.O. Box 2411, Earley, Reading, RG6 5FY, United Kingdom \\ 3. Physics, Chemistry and Instrumentation Laboratory, IAEA Laboratories Seibersdorf, International Atomic Energy Agency, PO \\ Box 100, Wagramerstrasse 5, A-1400 Vienna, Austria \\ 4. Soil and Water Management and Crop Nutrition Laboratory (SWMCNL), Joint FAO/IAEA Division of Nuclear Techniques in \\ Food and Agriculture, IAEA Laboratories Seibersdorf, International Atomic Energy Agency, PO Box 100, Wagramerstrasse 5, \\ A-1400 Vienna, Austria \\ 5. Institut Ruđer Bošković, Bijenička cesta 54, 10000 Zagreb, Croatia \\ 6. Plant Biotechnology Unit, Department of Biotechnology, University of Natural Resources and Applied Life Sciences, Muthgasse
} 18, A-1190 Vienna, Austria

\begin{abstract}
Salt is a major abiotic stress threatening crop plants such as rice. Tolerance to salt is complex and regulated by numerous genetic and non-genetic factors. To date most screens for salt tolerance rely on plant performance in stressed conditions. This article describes the ability to screen for salt tolerance in non-stressed conditions. The work is based on correlations between 62 rice genotypes in salt stress and non-stress conditions and measuring the intake of elements using Particle Induced X-ray Emission and $\mathrm{X}$-ray Fluorescence. Roots and shoots were analysed though shoots provided easier and more robust materials to work with. Data were interpreted using multivariate statistical analysis which showed the intake ratio of elements across tolerant, moderately tolerant and susceptible rice genotypes. Tolerant genotypes exhibited a larger intake of elements, and a classification criteria based on Canonical Discriminant Analysis allowed differentiation of salt tolerant genotypes not only under salt stress but, significantly, also under non-stressed conditions. Thus, shoot element content in benign conditions can be used as an indicator for salt tolerance. These studies suggest that many salt tolerance mechanisms in rice cultivars are constitutive, they are not switched on by stress, and this has implications for physiological and genetic studies, especially in crop plants. The approach has practical application as it allows pre-screening in non-stressed conditions, from which candidate salt tolerant genotypes may be selected for subsequent testing in saline field conditions, selecting in benign conditions provides greater seed harvest of the next generation which can be used in multiple tests.
\end{abstract}

Key words: Rice, non-stress salt tolerance screening, canonical discrimination analysis, shoot element content, element ratios.

\section{Introduction}

Soil salinity is prevalent in arid and semi-arid, and in coastal regions subject to inadequate irrigation and/or drainage. It is a major environmental constraint

\footnotetext{
*Corresponding author: Souleymane Bado, Ph.D., research assistant, research fields: mutagens, mutation induction, mutation breeding, cell/tissue culture, abiotic stresses and screening.
}

to crop productivity throughout the world [1-3], and especially problematic in irrigated agricultural systems. In general, salt tolerance in plants is associated with maintenance of growth and the ability to complete the life cycle. Salinity stress reduces growth and productivity [3, 4], and susceptible plants may die before reproduction. For crop plants salt tolerance may be generally defined as the ability to 
produce a yield in saline conditions.

Salt tolerance is often described as a complex trait, both genetically and physiologically [5]. In physiological terms salinity stress begins with low water potential in the root environment leading to a water deficit in the plant. This is followed by toxic effects of ions such $\mathrm{Na}^{+}$and $\mathrm{Cl}^{-}$on cells and tissues and results in a nutrient imbalance [6]. According to Munns and Tester [7] plants adapt to salinity through three distinct mechanisms: 1) osmotic adjustment, 2) ion exclusion and 3) tissue tolerance to the accumulation of toxic ions (particularly $\mathrm{Na}^{+}$or $\mathrm{Cl}^{-}$). Toxic elements often accumulate in older leaves, which is manifest by early senescence. When the death rate of older leaves is greater than the production of new leaves, the photosynthetic capacity drops and growth is retarded [7]. In salt tolerant genotypes, these mechanisms result in the maintenance of high shoot/root ratios and relatively high growth rates in saline conditions $[6,8,9]$. These complex physiological mechanisms often infer complex underlying genetics, which is problematic for plant breeders. Plant breeders are further constrained in that major genes, such developmental genes, e.g. those required by crops to grow in specific environments, often have pleiotropic effects on salt tolerance [10-12].

Rice is the most important cereal crop after maize in the

world (http://faostat.fao.org/site/339/default.aspx) in terms of production. With respect to human consumption rice is pre-eminent; over half of the world's population depends on rice as a staple food, particularly in Asia and Africa [13, 14]. Fairhurst and Dobermann [15] reported that irrigated rice accounted for $55 \%$ of the global harvested area and contributed to $75 \%$ of global rice production. Rice is classified as a salt sensitive crop [16] and is particularly sensitive to salt stress at the seedling stage, less so at flowering and maturity [17]. Among rice genotypes there is a range of tolerance; three classes have been identified (tolerant, moderate and susceptible) according to their response to salt stress [18]. The genetic variation for salt tolerance is of great interest as it provides potential for improvement through plant breeding.

Previous studies, based on traditional methods in assessing salt tolerance: root and shoot biomass production in salt treatments, have identified genotypes that can be used as standards for salt tolerance: tolerant, moderate and susceptible classes. Tolerance can be assessed using CID (Carbon isotope discrimination), which integrates plant performance/health over time and treatments. In our preliminary experiments, tissue element content was measured in six standard lines (two from each tolerance class) using atomic spectroscopy techniques (X-ray Fluorescence and Particle Induced X-ray Emission, a new application for these techniques). The data shows strong correlations with biomass production, which is a standard method for assessing salt tolerance. In order to validate these findings work was extended to a total of 62 rice genotypes from various regions and with known salt tolerances. Tests were carried out in saline and non-saline hydroponic conditions using a quick screening system developed by the International Rice Research Institute, IRRI [18] and modified by Plant Breeding and Genetics Laboratory PBGL [19].

\section{Materials and Methods}

\subsection{Confirmation of Salt Tolerance in 6 Standard Genotypes Using Biomass Data}

The six standard genotypes, 2 from each class (tolerant, moderate and susceptible) were checked for salt tolerance using root and shoot biomass data from hydroponics experiments in control and salt treatments. This confirmed the salt tolerance classes of the standard genotypes, which were then used in subsequent experiments, and provided information for optimum harvest data for biomass evaluation (16 days after salt treatment). 


\subsubsection{Plant Material}

Six rice genotypes with known responses to salinity were used (data on the salt tolerance of these genotypes can be found in http://irri.org/our-science/genetic-diversity): two tolerant - 'Pokkali' and 'Nona Bokra', two of moderate tolerance - 'Bicol' and 'STDV', and two susceptible - 'IR29' and 'Taipei 309'. Genotypes 'Pokkali' and 'Nona Bokra' are both traditional tall, Indica rice cultivars from India. 'Bicol' is a relatively newly released moderately salt tolerant Indica cultivar derived from anther culture of an $\mathrm{F}_{1}$ hybrid between IR5657-33-2 and IR4630-22-2-5-1-3 and 'STDV' is an anther culture derived semi-dwarf genotype from 'IR29' and classed as moderately tolerant. 'IR29' is a modern semi-dwarf Indica rice cultivar from IRRI, Philippines, and is susceptible to salinity; 'Taipei 309' is a Japonica cultivar also known to be susceptible to salinity. All six standard rice genotypes were obtained from IRRI.

\subsubsection{Hydroponic Experiments}

Hydroponic experiments were carried out in a glasshouse (temperature approx. day/night of: $30 / 20{ }^{\circ} \mathrm{C}$ $\left( \pm 2{ }^{\circ} \mathrm{C}\right)$ with $50-70 \%$ relative humidity provided by misting). Seeds were pre-germinated in Petri dishes on filter paper with distilled water. Germinated seeds were transferred to mesh supports in contact with the surface of a hydroponic solution. After 2 weeks the seedlings were removed carefully and wrapped in sponge strips and transferred to test hydroponic tanks. A modified Yoshida nutrient solution was used in the hydroponic system $[19,20]$. Two treatments were set up, a control (no added $\mathrm{NaCl}$ ) and a salt treatment $(\mathrm{NaCl}, 10 \mathrm{dS} / \mathrm{m}$ or approximately $6.4 \mathrm{mg} / \mathrm{L} \mathrm{NaCl})$. These were applied after seedling establishment in hydroponics to four weeks old seedlings. Hydroponic solutions were replenished every 2-3 days. Details of the hydroponics protocol can be found at: http://www-naweb.iaea.org/nafa/pbg/public/manuals-p bg.html. Plant distribution was set up as a completely randomized design in the glasshouse with three replications per treatment and ten plants per replication.

\subsection{Element Composition Analysis}

The six standard genotypes were analysed for element composition at 0,12 and 16 days after salt treatment using atomic spectroscopy methods. Correlations were found with biomass and the element data could be used to discriminate between the three classes. A new finding was that patterns for element discrimination which were similar in control (no salt) and salt treatments, suggesting that salt tolerance could be evaluated in control conditions. 16 days proved to be the most informative harvest time for shoot element analysis.

\subsubsection{Biomass Analysis}

Plants of the six standard genotypes were sampled at $0,4,8,12$ and 16 days after treatment initiation (DAT). Growth parameters such as shoot and root biomass (fresh and dry weight), height and tiller number were used as a basis for determining salt tolerance. Roots of harvested plants were washed with water and gently blot-dried with paper tissue before recording fresh weight, plant height and number of tillers. Thirty plants were sampled per genotype per treatment, in total 360 plants per sampling time. For dry weight determination, shoots and roots were oven-dried at $70{ }^{\circ} \mathrm{C}$ for four days and then weighed.

2.2.2 Element Composition Analyses of Standard Genotypes

The biomass data were compared with element content data which were determined by X-ray Fluorescence spectrometer (XRF), see below. Shoots were sampled for each standard genotype at 0,12 and 16 days after treatment initiation (DAT) using hydroponic tests as described above.

\subsection{Validation Experiment}

The study was extended to 62 rice genotypes of documented salt tolerance to validate the finding that element up-take in control conditions reflected 
responses in salt stress conditions. Element data were compared with shoot biomass data and CID data.

\subsubsection{Validation Experiment}

62 rice genotypes with known responses to salinity were used as plant materials, this included the six standards. These comprised 23 tolerant, 13 moderately tolerant and 26 susceptible genotypes (Table 1). These genotypes were sourced mainly from IRRI, in addition to salt tolerance criteria; the rice genotypes were selected from a range of countries and include contemporary as well as traditional cultivars. Growth parameters such as shoot biomass (fresh and dry weights), height and tiller number were used as a basis for determining genotype performance under salinity. For dry weight determination, shoots and roots were oven-dried at $70{ }^{\circ} \mathrm{C}$ for four days and weighed. Then the shoots samples were ground to fine powder for carbon isotope discrimination and elements contents by spectrometry.

\subsubsection{Carbon Isotope Discrimination}

CID has been used as a surrogate for salt tolerance in many studies [21-24]. Dried shoot samples of sixty genotypes from untreated and treated conditions were weighed and sealed into $8 \times 5 \mathrm{~mm}$ tin cups, then loaded into the auto-sampler of an EA (Elemental Analyzer) (Flash 2000, Thermo Scientific, Massachusetts, USA) coupled to an Isotope Ratio Mass Spectrometry (IRMS) (Isoprime, GV Instruments, Manchester, UK). The samples were flash combusted in a temporarily oxygen-enriched atmosphere of a combustion reactor (chromium oxide, silvered cobaltous/cobaltic oxide, quartz wool) held at $1,020^{\circ} \mathrm{C}$. The oxidation products

Table 1 Rice genotypes used, their origin and level of salt tolerance (standards in bold).

\begin{tabular}{|c|c|c|c|c|c|}
\hline \multicolumn{2}{|c|}{ Susceptible } & \multicolumn{2}{|l|}{ Moderate } & \multicolumn{2}{|l|}{ Tolerant } \\
\hline Genotype & Origin & BG 94-2 & Sri Lanka & Genotype & Origin \\
\hline BPT3402 & India & DAMODAR & India & BHURA RATA 4-10 & India \\
\hline BR4 & India & GETU & India & AKUNDO & Bangladesh \\
\hline $\mathrm{C} 5$ & United States & IR51491-AC5-1 & IRRI & CHERIVIRUPPU & India \\
\hline Giza 171 & Egypt & POKKALI & Sri Lanka & IR 66946-3R-116-1-1 & IRRI \\
\hline HABA & Philippines & POKKALI (8558) & Sri Lanka & IR 66946-3R-149-1-1 & IRRI \\
\hline IET1444 & India & IR 77660-B-9-1-3-2-1-7-5-1 & IRRI & IR 58443-6B-10-3 & Philippines \\
\hline IR24 & Philippines & IR 83460-4-B-4-2-1-1 & IRRI & IRRI 147 & IRRI \\
\hline IR29 & Philippines & IR 84115-10-B-AJY3-1-1 & IRRI & IR 66946-3R-178-1-1 & IRRI \\
\hline M117 & India & IR 84084-B-B-1-1 & IRRI & IR11T189 & IRRI \\
\hline MADHUKAR & India & IR83420-B-AJY3-8-SDO1 & IRRI & IR11T222 & IRRI \\
\hline SR 26B & Japan & Bicol (IAEA) & IRRI & NONA BOKRA & India \\
\hline SUWON 143 & Republic of Korea & STDV(IAEA) & IAEA & POKKALI 108921 & India \\
\hline KUATIK BENE & Indonesia & BG 94-2 & Sri Lanka & ТCCP 266-1-3B-13-1-3 & IRRI \\
\hline MK47-22 & India & DAMODAR & India & HASAWI & Saudi Arabia \\
\hline SINDANO & Kenya & & & IR 4630-22-2-5-1-3 & IRRI \\
\hline DHALIBORO 94 & Bangladesh & & & CSR28 & India \\
\hline GASMAL 72-1 & Bangladesh & & & AT 401 & Sri Lanka \\
\hline BINADHAN 7 & Bangladesh & & & IR 72046-B-R-3 & IRRI \\
\hline BR 28 & Bangladesh & & & CAPSULE & Bangladesh \\
\hline BR 29 & Bangladesh & & & A $69-1$ & Sri Lanka \\
\hline NSIC Rc 222 & Unknown & & & IR 55179-3B-11-3 & IRRI \\
\hline IR29 & Philippines & & & NONA BOKRA (IAEA) & India \\
\hline SADRI & Iran & & & POKKALI (IAEA) & Sri Lanka \\
\hline $\begin{array}{l}\text { TAIPEI } 309 \\
\text { (IAEA) }\end{array}$ & Taiwan & & & & \\
\hline IR29 (IAEA) & Philippines & & & & \\
\hline NIPPON BARE & Japan & & & & \\
\hline
\end{tabular}


were carried by a stream of helium through a reduction reactor (copper, quartz chips, quartz wool) at $650{ }^{\circ} \mathrm{C}$. The resulting gases (primarily $\mathrm{CO}_{2}, \mathrm{~N}_{2}$ and $\mathrm{H}_{2} \mathrm{O}$ ) were then carried through a magnesium perchlorate filter to remove water. The $\mathrm{CO}_{2}$ and $\mathrm{N}_{2}$ were separated in a packed chromatographic column, passed through a thermal conductivity detector, and carried into the source of the IRMS where the isotope ratios were measured against a pulse of reference gas of known isotopic composition. The carbon and nitrogen yields were estimated with a standard of known carbon and nitrogen content (laboratory standard S19) and calibration achieved from a regression of peak area versus the carbon and nitrogen content of the standard.

\subsubsection{Element Composition}

The elemental composition of the samples was analysed by XRF (X-ray Fluorescence) and PIXE (Particle Induced X-ray Emission). In total, fourteen elements were analysed: $\mathrm{Na}, \mathrm{Mg}, \mathrm{P}, \mathrm{S}, \mathrm{Cl}, \mathrm{K}, \mathrm{Ca}, \mathrm{Mn}$, $\mathrm{Fe}, \mathrm{Cu}, \mathrm{Zn}, \mathrm{Br}, \mathrm{Rb}$ and $\mathrm{Sr}$. Shoot samples from three independent ten seedlings for each genotype were collected for both, control and exposed to salinity stress experiments. $0.5 \mathrm{~g}$ of milled shoots were pressed into a pellet (25 mm diameter) and prepared for both PIXE and XRF measurements.

Ten different certified RMs (Reference materials) of vegetable origin were used for calibration: brown bread (BCR191), cabbage (IAEA 359), hay (IAEA-V10), lichen (BCR 482), mixed polish herbs (INCT-MPH-2), olive leaves (BCR 62), orchard leaves (NBS1571), rye flour (IAEA-V8), spinach leaves (NBS1570A) and tea leaves (INCT-TL-1). Another RM of biological origin (milk powder, IAEA A11) was added to the list to enlarge the number of values for the concentration range of some elements, such as $\mathrm{Cl}, \mathrm{Mn}, \mathrm{Cu}$ and $\mathrm{Rb}$.

For XRF, a spectrometer based on the use of a Pd-anode X-ray tube in combination with different secondary emission/scattering targets for excitation was used. Three excitation-measurement conditions were selected as to improve the X-ray production of different groups of elements as follows: Secondary Target (ST) of molybdenum (for $\mathrm{Fe}, \mathrm{Cu}, \mathrm{Zn}, \mathrm{Br}, \mathrm{Rb}$, $\mathrm{Sr}$ ); Cobalt ST (for K, Ca, Mn) and; HOPG (Highly Oriented Pyrolytic Graphite scatter element) for the excitation of low atomic number elements $(\mathrm{Mg}, \mathrm{P}, \mathrm{S}$ and $\mathrm{Cl}$ ). Linear calibrations were made for quantification of each of the elements at the selected condition by measuring the RMs mentioned above. The calibrations were based on using selected energy radiation scattered at the sample as internal normalization of the measured fluorescent signal of each element to compensate for sample self-attenuation [25].

For PIXE, the measurements were made with a Silicon Drift Detector arranged in a configuration improved for the detection of low atomic number elements. The quantification was made based on determining individual geometry factors (H-values) for each element by measuring three different RMs. As the pellets cannot be considered as being electrically conductive, the effective charge deposited in the samples was determined by RBS (Rutherford Backscatter Spectrometry). The measured spectra were analysed using dedicated software (GUPIX for PIXE and SIMNRA for RBS). More details of XRF and PIXE can be found in Bado et al. [26].

\subsubsection{Statistical Analysis}

Data were recorded for $\mathrm{P}, \mathrm{K}, \mathrm{Ca}$ and $\mathrm{Mg}$ (macro-elements) and $\mathrm{Fe}, \mathrm{Mn}, \mathrm{Zn}, \mathrm{Cu}, \mathrm{Cl}$, and $\mathrm{Na}$ (micro-elements) in shoot and root samples. In addition to the raw data, various salt tolerance indices were calculated including: $\mathrm{K}: \mathrm{Na}, \mathrm{Ca}: \mathrm{Na}, \mathrm{Mg}: \mathrm{Na}$, and $\mathrm{Na}: \mathrm{Cl}$ ratios in shoots [27-33]. Mean values were evaluated at $5 \%$ significance level $(\mathrm{P} \leq 0.05)$ and in case of detection of significance different means were compared using Duncan's test.

The main steps followed for the multivariate statistical interpretation of the measured elemental concentrations were the following: (a) Multiplying the concentration values by the dry mass of the samples, in order to obtain the total amount of nutrients intake 
by the plant; b) Transforming the resulting data to log 10 values, to avoid uneven concentration ranges of the elements that might impose different weights in subsequent analyses; (c) Reducing of the dimensionality of the data space using PCA (Principal Component Analysis) to ease the interpretation, and in the search for some ordination; (d) Establishing a classification criterion based on using two Canonical Discriminant Functions to differentiate three classes in the data set (tolerant, medium tolerance and susceptible varieties) and evaluation of group membership probabilities using CDA (Canonical Discriminant Analysis). The statistical interpretation was performed using the procedures included in the software SPSS 11.5.

\section{Results}

\subsection{Confirmation of Salt Tolerance in Standard Genotypes}

The biomass data were in accordance with the known salt tolerances of the 6 standard genotypes. The EC $10 \mathrm{dS} / \mathrm{m} \mathrm{NaCl}$ salt stress treatment had a major effect on growth with respect to plant height, fresh and dry weight. However, no significant difference was recorded between genotypes for tiller number during the time course of the experiment. 'IR29' exhibited the biggest reduction in plant height at $\mathrm{p} \leq 0.05$. At 16 DAT both susceptible genotypes, 'Taipei 309' and 'IR29' were affected most by salinity when compared with the salt tolerant genotypes, 'Pokkali' and 'Nona Bokra' (Table 2).

The least dry weight reduction percentage was observed in the tolerant genotype 'Nona Bokra' (16.4\% and $7.1 \%$ respectively for shoot and root), and the greatest reduction was recorded for 'Taipei 309' (40.4\% and $58.3 \%$ for shoot and root).

The salt treatment induced stationary or decreased biomass production with effects beginning to show differences among genotypes at 12 DAT (Fig. 1), as a consequence sampling at 0,12 and 16 DAT were chosen for element compositional analysis by XRF. The tolerant genotypes 'Pokkali' and 'Nona Bokra' showed the least growth retardation (Fig. 1).

\subsection{Element composition of standard genotypes}

The element analysis of the 6 standard genotypes was used to study discrimination under salt stress and control treatments. Ratios of $\mathrm{K}, \mathrm{Ca}, \mathrm{Mg}$ and $\mathrm{Cl}$ with $\mathrm{Na}$ were associated with salt tolerance under treated than untreated condition (Table 3).

\subsection{Validation Experiment}

Element composition was determined using atomic spectroscopy and the data compared with biomass and CID measurements. Atomic spectroscopy was carried out using Particle Induced PIXE and XRF. Na, Mg, P, $\mathrm{S}$ and $\mathrm{Cl}$ were measured accurately with PIXE and $\mathrm{Ca}$, $\mathrm{Mn}, \mathrm{Fe}, \mathrm{Cu}, \mathrm{Zn}, \mathrm{Br}, \mathrm{Rb}$ and $\mathrm{Sr}$ were measured accurately

Table 2 Mean biomass data for each standard genotype at $16 \mathrm{DAT}(\mathrm{NaCl}, 10 \mathrm{dS} / \mathrm{m})$.

\begin{tabular}{|c|c|c|c|c|}
\hline Genotype & $\begin{array}{l}\text { Plant height } \\
(\mathrm{cm})\end{array}$ & $\begin{array}{l}\text { Whole plant fresh weight } \\
(\mathrm{g})\end{array}$ & $\begin{array}{l}\text { Shoot dry weight } \\
(\mathrm{g})\end{array}$ & $\begin{array}{l}\text { Root dry weight } \\
(\mathrm{g})\end{array}$ \\
\hline 'Pokkali' & $\begin{array}{l}80.33 \mathrm{a} \\
{[20.2]}\end{array}$ & $\begin{array}{l}6.95 \mathrm{~b} \\
{[43.0]}\end{array}$ & $\begin{array}{l}0.89 \mathrm{~b} \\
{[31.5]}\end{array}$ & $\begin{array}{l}0.17 \mathrm{~b} \\
{[20.3]}\end{array}$ \\
\hline 'Nona Bokra' & $\begin{array}{l}86.99 \mathrm{a} \\
{[21.3]}\end{array}$ & $\begin{array}{l}12.02 \mathrm{a} \\
{[29.0]}\end{array}$ & $\begin{array}{l}1.5 \mathrm{a} \\
{[16.4]}\end{array}$ & $\begin{array}{l}0.26 \mathrm{a} \\
{[07.1]}\end{array}$ \\
\hline 'Bicol' & $\begin{array}{l}48.01 \mathrm{~b} \\
{[22.0]}\end{array}$ & $\begin{array}{l}3.33 \mathrm{c} \\
{[37.7]}\end{array}$ & $\begin{array}{l}0.49 \mathrm{c} \\
{[28.0]}\end{array}$ & $\begin{array}{l}0.10 \mathrm{c} \\
{[31.8]}\end{array}$ \\
\hline 'STDV' & $\begin{array}{l}48.10 \mathrm{~b} \\
{[27.0]}\end{array}$ & $\begin{array}{l}3.08 \mathrm{c} \\
{[55.0]}\end{array}$ & $\begin{array}{l}0.44 \mathrm{~cd} \\
{[36.3]}\end{array}$ & $\begin{array}{l}0.10 \mathrm{c} \\
{[50.0]}\end{array}$ \\
\hline 'Taipei 309' & $\begin{array}{l}42.47 \mathrm{~b} \\
{[30.7]}\end{array}$ & $\begin{array}{l}0.94 \mathrm{~d} \\
{[48.7]}\end{array}$ & $\begin{array}{l}0.16 \mathrm{~d} \\
{[40.4]}\end{array}$ & $\begin{array}{l}0.03 \mathrm{~d} \\
{[58.3]}\end{array}$ \\
\hline 'IR29' & $\begin{array}{l}37.54 \mathrm{c} \\
{[31.9]}\end{array}$ & $\begin{array}{l}2.16 \mathrm{~cd} \\
{[47.6]}\end{array}$ & $\begin{array}{l}0.31 \mathrm{~cd} \\
{[39.8]}\end{array}$ & $\begin{array}{l}0.06 \mathrm{~cd} \\
{[45.0]}\end{array}$ \\
\hline
\end{tabular}

*Means followed by same small letters denote no significant difference among genotypes at $10 \mathrm{dS} / \mathrm{m}$ salinity. [value]: \% reduction compared to control. 


\section{Content under Non-Stressed Conditions}
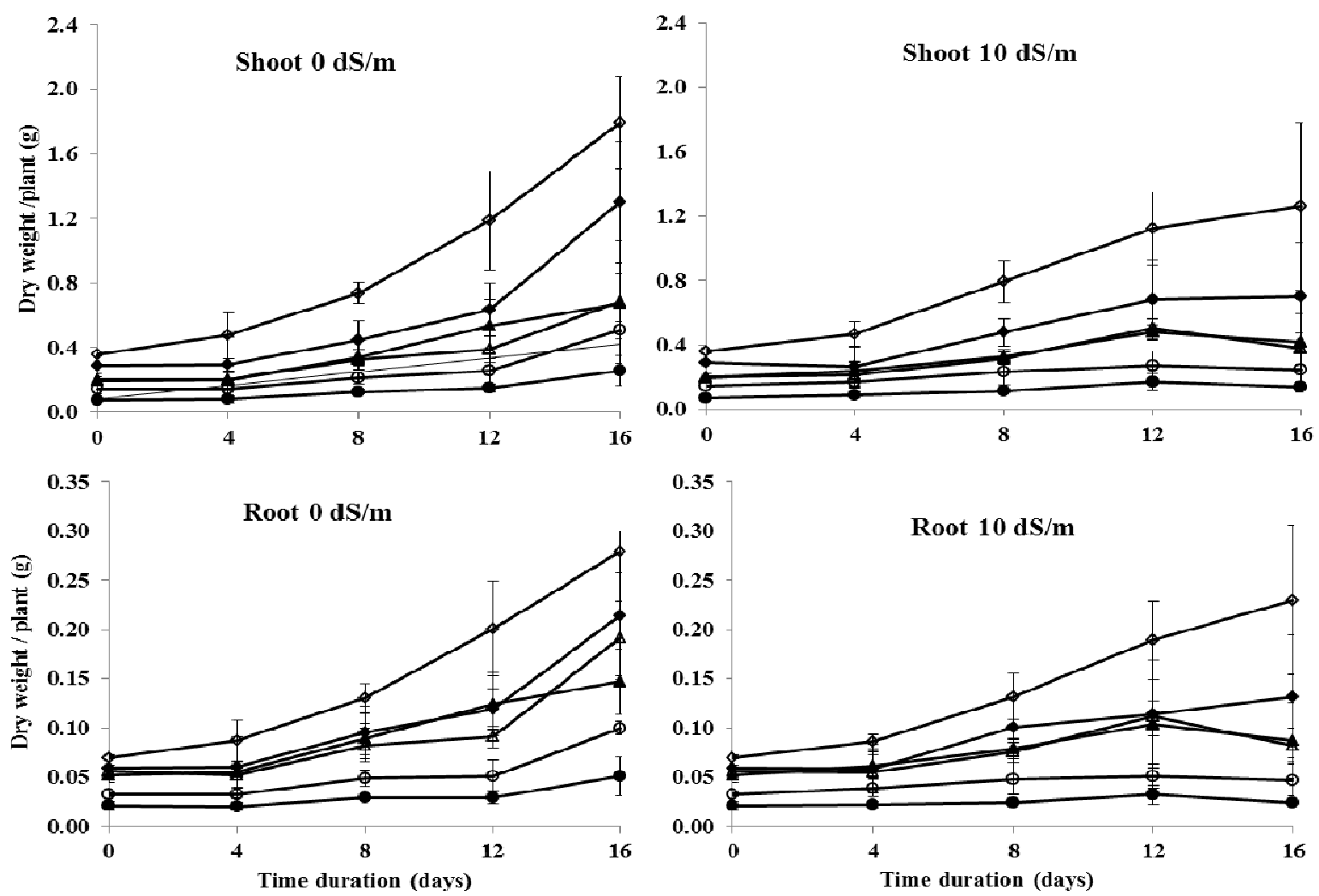

Fig. 1 Shoot and root dry weight at 0, 4, 8, 12 and 16 DAT for the six standard rice genotypes from two treatments (0 and 10 $\mathrm{dS} / \mathrm{m}$ ). Each point represents the results of mean of 10 plants per genotype Tolerant genotypes: square symbol (solid: 'Pokkali' and open: 'Nona Bokra'); Moderate tolerant genotypes: Triangle symbol (solid: 'Bicol' and open: 'STDV'); Susceptible genotypes: round symbol (solid: ‘Taipei 309’ and open: ‘IR29').

Table 3 Ratios of elements (K, Ca, Mg and $\mathrm{Cl}$ ) with $\mathrm{Na}$ in the standard rice genotypes at 0 and $16 \mathrm{DAT}$ under $10 \mathrm{dS} / \mathrm{m}$.

\begin{tabular}{|c|c|c|c|c|c|c|}
\hline \multirow{2}{*}{ Genotype } & \multicolumn{2}{|c|}{ Duration/Treatment } & \multicolumn{4}{|c|}{ Mean element ratio } \\
\hline & Day & $\mathrm{EC}(\mathrm{dS} / \mathrm{m})$ & $\mathrm{K}: \mathrm{Na}$ & $\mathrm{Ca}: \mathrm{Na}$ & $\mathrm{Mg}: \mathrm{Na}$ & $\mathrm{Na}: \mathrm{Cl}$ \\
\hline \multirow{3}{*}{ ‘Pokkali’ } & 0 & 0 & $2.31 \mathrm{a}$ & $1.46 \mathrm{ab}$ & $1.87 \mathrm{c}$ & 0.51 \\
\hline & \multirow{2}{*}{16} & 0 & $2.45 \mathrm{ab}$ & $1.44 \mathrm{ab}$ & $1.85 \mathrm{c}$ & $0.38 \mathrm{bc}$ \\
\hline & & 10 & $1.32 \mathrm{a}$ & $1.42 \mathrm{a}$ & $0.51 \mathrm{a}$ & $0.47 \mathrm{bc}$ \\
\hline \multirow{3}{*}{ 'Nona Bokra' } & 0 & 0 & $2.18 \mathrm{ab}$ & $1.70 \mathrm{a}$ & $3.02 \mathrm{a}$ & 0.52 \\
\hline & \multirow{2}{*}{16} & 0 & $2.92 \mathrm{a}$ & $1.54 \mathrm{ab}$ & $2.31 \mathrm{~b}$ & $0.27 \mathrm{c}$ \\
\hline & & 10 & $1.20 \mathrm{ab}$ & $1.20 \mathrm{ab}$ & $0.69 \mathrm{a}$ & $0.28 \mathrm{c}$ \\
\hline \multirow{3}{*}{ ‘Bicol’ } & 0 & 0 & $1.70 \mathrm{abc}$ & $1.25 \mathrm{ab}$ & $2.44 \mathrm{~b}$ & 0.70 \\
\hline & \multirow{2}{*}{16} & 0 & $2.15 \mathrm{bc}$ & $1.64 \mathrm{a}$ & $2.68 \mathrm{a}$ & $0.46 \mathrm{bc}$ \\
\hline & & 10 & $0.57 \mathrm{bc}$ & $0.79 \mathrm{abc}$ & $0.26 \mathrm{~b}$ & $0.63 \mathrm{~b}$ \\
\hline \multirow{3}{*}{ ‘STDV’ } & 0 & 0 & $1.53 \mathrm{bc}$ & $1.15 \mathrm{ab}$ & $2.74 \mathrm{ab}$ & 0.66 \\
\hline & \multirow{2}{*}{16} & 0 & $1.92 \mathrm{bc}$ & $1.44 \mathrm{ab}$ & $2.41 \mathrm{ab}$ & $0.48 \mathrm{bc}$ \\
\hline & & 10 & $0.60 \mathrm{bc}$ & $0.78 \mathrm{abc}$ & $0.20 \mathrm{~b}$ & $0.65 \mathrm{~b}$ \\
\hline \multirow{3}{*}{ ‘Taipei 309’ } & 0 & 0 & $1.31 \mathrm{c}$ & $1.06 \mathrm{~b}$ & $2.41 \mathrm{~b}$ & 0.98 \\
\hline & \multirow{2}{*}{16} & 0 & $1.17 \mathrm{~d}$ & $1.02 \mathrm{~b}$ & $2.58 \mathrm{ab}$ & $0.98 \mathrm{a}$ \\
\hline & & 10 & $0.17 \mathrm{c}$ & $0.38 \mathrm{c}$ & $0.07 \mathrm{~b}$ & $1.01 \mathrm{a}$ \\
\hline \multirow{3}{*}{ ‘IR29’ } & 0 & 0 & $1.20 \mathrm{c}$ & $1.38 \mathrm{ab}$ & $2.72 \mathrm{ab}$ & 0.95 \\
\hline & \multirow{2}{*}{16} & 0 & $1.77 \mathrm{c}$ & $1.43 \mathrm{ab}$ & $2.66 \mathrm{a}$ & $0.53 \mathrm{~b}$ \\
\hline & & 10 & $0.28 \mathrm{c}$ & $0.61 \mathrm{bc}$ & $0.09 \mathrm{~b}$ & $\mathrm{~b}$ \\
\hline
\end{tabular}

*Ratios followed by the same letters for specific ratios (i.e. within columns) denote non-significant difference among genotypes in the same treatment. 
with XRF analysis. The ratios of $\mathrm{K}, \mathrm{Ca}, \mathrm{Mg}$ and $\mathrm{Cl}$ with $\mathrm{Na}$ of the 62 rice genotypes were scattered among the salt tolerance. These ratios under treated and control (no $\mathrm{NaCl}$ ) conditions did not show a clear differentiation of tolerant and susceptible genotypes. The data also showed the scattering of biomass performance of the 62 rice genotypes under the 10 $\mathrm{dS} / \mathrm{m} \mathrm{NaCl}$. Therefore the elemental intake results were re-scaled to $\log -10$ values, and the extracted PCA components were rotated using the Varimax method [34, 35], in order to provide greater agreement between axes and variable correlation, thus allowing a better interpretation of the observed differences in elemental contents due salt treatments. The coefficients of each of the original variables (elemental concentration) in extracted principal components (principal component loadings) provide information for the identification of correlated variables and their contribution to the variability in the data set.

The tendency in the variations of concentrations of the fourteen elements in the different genotypes was explored for the two data sets containing the control and exposed to salinity stress samples, respectively. The results of the PCA are summarized in Tables 4 and 5, and revealed that the two first components accounted for $65 \%$ and $23 \%$ of variability of the data set, respectively (Table 4). The largest variability in the data set, nearly $65 \%$ is accounted for by the nutrient elements (see larger loading values in Table 4), even larger than the contribution to variability due to the elements related to the salinity stress $(\mathrm{Na}, \mathrm{Cl}$ and $\mathrm{Br})$. The tendency in variations of the elemental mass fractions with salt status and treatment can be observed from Fig. 2 .

Each sample is represented in Fig. 2 as occupying a location by its principal component scores in the $2 \mathrm{D}$ space formed by the first extracted principal components. As samples are labelled according to their tolerance and the exposure to salt treatment at which the plant tissue was collected, it can be observed from this ordination that there is a marked difference in the composition of the samples. The ordination of the samples in the PC space reveals two groups corresponding to the exposure to salt levels: treated samples appear clustered in the upper left area of the graph whereas untreated appear in the lower right area. The results obtained for the samples that underwent saline treatment show that there is a decrease in the intake of nutrients $\mathrm{Mg}, \mathrm{P}, \mathrm{S}, \mathrm{K}, \mathrm{Ca}$, $\mathrm{Mn}, \mathrm{Fe}, \mathrm{Cu}$ and $\mathrm{Zn}$ compared to the control (non-salt treated) samples. The decrease is more pronounced for the susceptible genotypes, whereas tolerant ones exhibit a larger intake of these elements. All elements showed a decrease under salt stress except for $\mathrm{Na}$ and $\mathrm{Cl}$ which accumulated in the shoots.

PCA analysis (Fig. 2) showed differentiation between the treatments and genotype tolerance to salinity.

Table 4 Eigenvectors and percent of variance explained the variation in principal component analysis.

\begin{tabular}{|c|c|c|c|c|c|c|c|c|c|}
\hline \multirow[b]{2}{*}{ Component } & \multicolumn{3}{|c|}{ Initial eigenvalues } & \multicolumn{3}{|c|}{ Extraction sums of squared loadings } & \multicolumn{3}{|c|}{ Rotation sums of squared loadings } \\
\hline & Total & $\begin{array}{l}\% \text { of } \\
\text { variance }\end{array}$ & Cumulative $\%$ & Total & $\begin{array}{l}\% \text { of } \\
\text { variance }\end{array}$ & Cumulative $\%$ & Total & $\begin{array}{l}\% \text { of } \\
\text { variance }\end{array}$ & Cumulative \% \\
\hline 1 & 7.854 & 65.452 & 65.452 & & & & & & \\
\hline 2 & 2.734 & 22.784 & 88.236 & & & & & & \\
\hline 3 & .489 & 4.074 & 92.310 & & & & & & \\
\hline 4 & .204 & 1.697 & 94.007 & & & & & & \\
\hline 5 & .159 & 1.322 & 95.329 & & & & & & \\
\hline 6 & .135 & 1.126 & 96.455 & 7.854 & 65.452 & 7.808 & 7.808 & 65.068 & 65.068 \\
\hline 7 & .108 & .903 & 97.359 & 2.734 & 88.236 & 2.780 & 2.780 & 23.168 & 88.236 \\
\hline 8 & .098 & .819 & 98.178 & & & & & & \\
\hline 9 & 0.78 & .650 & 98.828 & & & & & & \\
\hline 10 & .064 & .536 & 99.364 & & & & & & \\
\hline 11 & .052 & .434 & 99.798 & & & & & & \\
\hline 12 & .024 & .202 & 100.000 & & & & & & \\
\hline
\end{tabular}




\section{Content under Non-Stressed Conditions}

Table 5 Factor loadings in the rotated component Matrix explaining the variation in principal component analysis. Factor extracted by Rotation Method from Varimax with Kaiser Normalization.

\begin{tabular}{llcll}
\hline & \multicolumn{3}{c}{ Raw } & \multicolumn{2}{c}{ Rescaled } \\
\cline { 2 - 5 } Element & \multicolumn{3}{c}{ Component } & Component \\
\cline { 2 - 5 } & .243 & 2 & .964 & -.093 \\
\hline L_TK & .193 & -.024 & .960 & -.046 \\
L_TS & .225 & -.009 & .946 & -.014 \\
L_TFE & .171 & .003 & .933 & .106 \\
L_TP & .208 & -019 & .932 & -.031 \\
L_TMG & .158 & .007 & .921 & .156 \\
L_TCU & .158 & .027 & .913 & .182 \\
L_TZN & .137 & .037 & .890 & .243 \\
L_TCA & .156 & -.001 & .784 & -.004 \\
L_TMN & .047 & .268 & .166 & .955 \\
L_TCL & -.246 & .680 & -.340 & .939 \\
L_TNA & .062 & .215 & .257 & .893 \\
L_TBR & & &
\end{tabular}

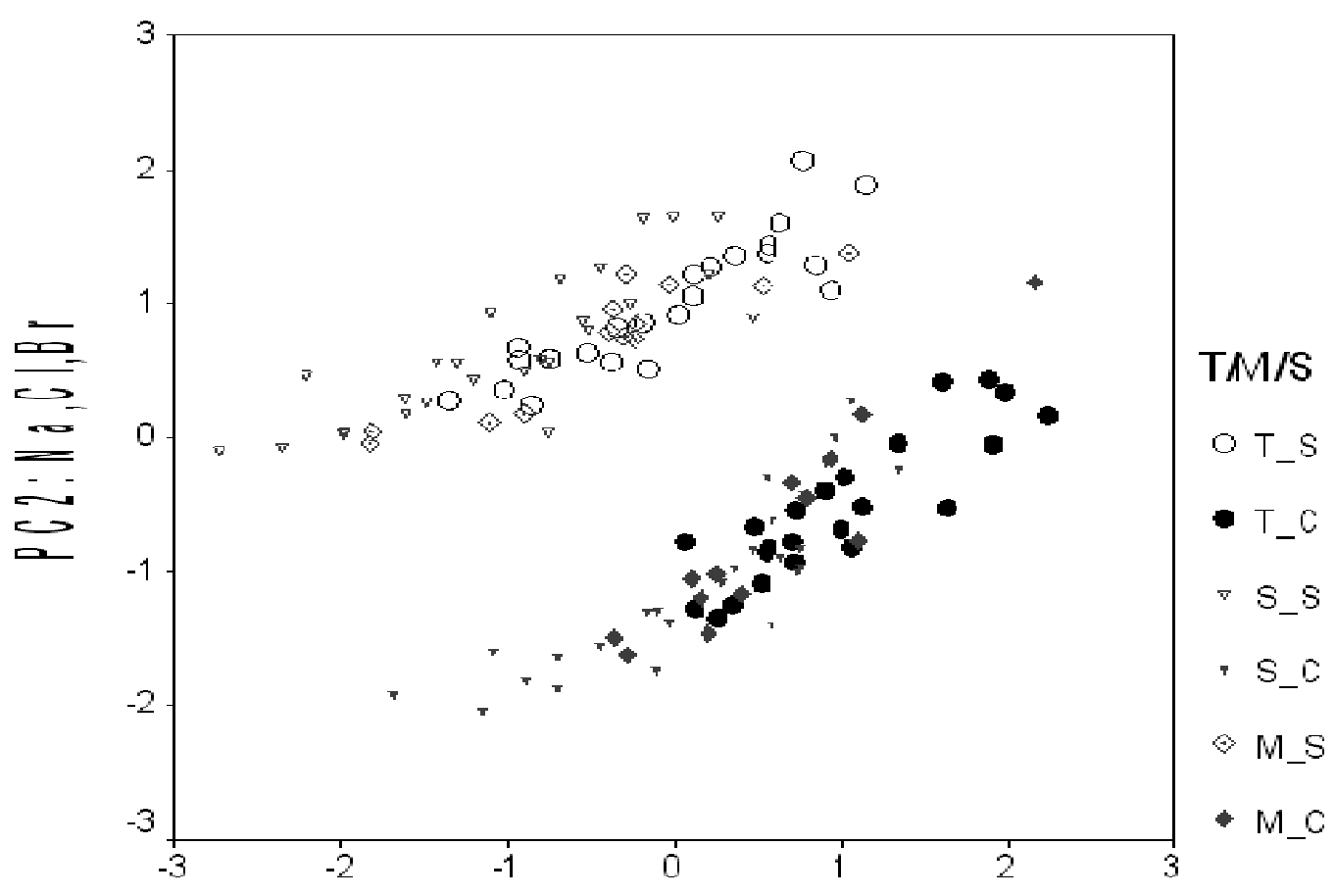

\section{$\mathrm{PC1}: \mathrm{Mg}, \mathrm{P}, \mathrm{S}, \mathrm{K}, \mathrm{Ca}, \mathrm{Mn}, \mathrm{Fe}, \mathrm{Cu}, \mathrm{Zn}$}

Fig. 2 Ordination of the samples according to their scores in the PC-space. Each point represents the results for individual genotype samples, which is in turn labelled according to the tolerance to salt ( $\mathrm{S}$ - susceptible, $\mathrm{M}$ - Moderate, T- tolerant genotypes) and to the group C - Control, S - Salt treated. Note that the pattern for control genotype (closed symbols) shows a strong similarity to the pattern of salt treatment data (open symbols).

These clusterings were less pronounced for root data in the analysis of standard genotypes. As a consequence the untreated shoot data set from validation experiment was explored for differentiation under control condition in a CDA.

These observations support the feasibility of classifying the rice genotypes into three tolerance classes, based on the contents of elements in seedling 
shoots. Linear discriminant analysis is a method commonly used in statistics to find linear combination of property values allowing separating two or more classes of objects. Canonical discriminant analysis aims to find linear and uncorrelated functions defining a $k-1$ canonical functions that allow achieving a better separation of $k$ expected classes. CDA also allows calculating the probability of belonging to a particular class.

The results of such interpretation of the results obtained for the entire population of control shoot samples are represented in Fig. 3. The probability of belonging to its assumed class was found to be more than $75 \%$ for the majority of tolerant and susceptible genotypes, over $80 \%$ of all cases. The canonical analysis allowed the three salt tolerant classes (tolerant, moderate tolerant and susceptible) to be separated.

The element composition data were compared to CID. CID in shoot tissues at 16 DAT (16 DAT was chosen as it gave the best salt tolerance differentiation for biomass). The CID plotted with the dry matter revealed significant differences between untreated and treated shoot samples and genetic variability among the rice genotypes (Fig. 4). The value of CID ranged from -30.86 to -28.73 and -30.19 to -27.64 respectively for untreated and treated shoot indicating that under salt stress CID became more positive. Obtained results allowed the clustering of untreated and treated samples with quite clear differentiation of the tolerant, moderate tolerant and susceptible genotypes.

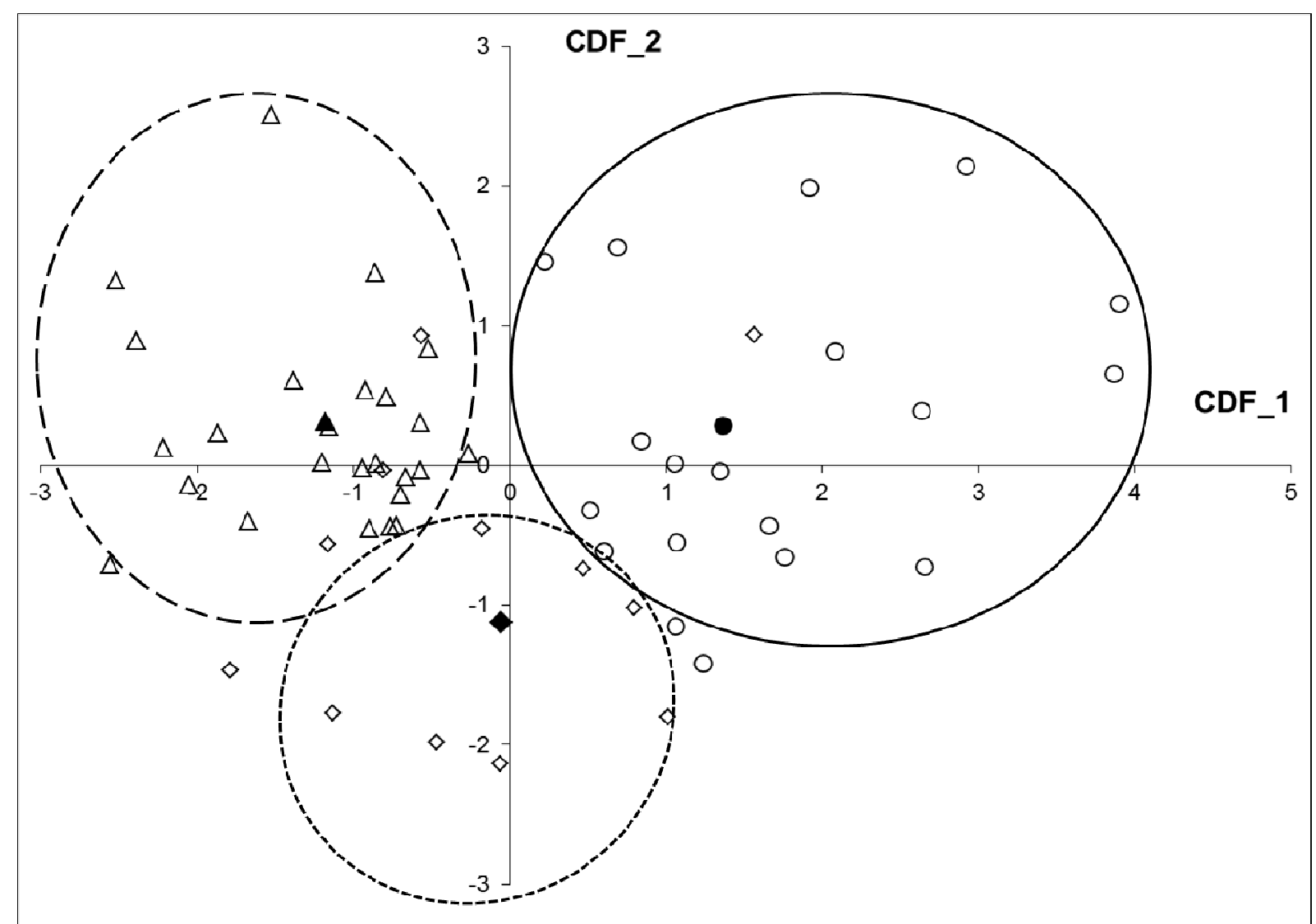

Fig. 3 Clustering of rice genotypes with known salt tolerance into the three salt tolerant classes based on conical discrimination analysis of 16 DAT shoot element content. The mid-point for each cluster is indicated by a solid symbol. Each open symbol represents the mean of three replications of ten plants per individual genotype samples, which is in turn labelled according to the tolerance to salt. Triangle symbol: susceptible, square symbol: moderate, round symbol: tolerant genotypes). 


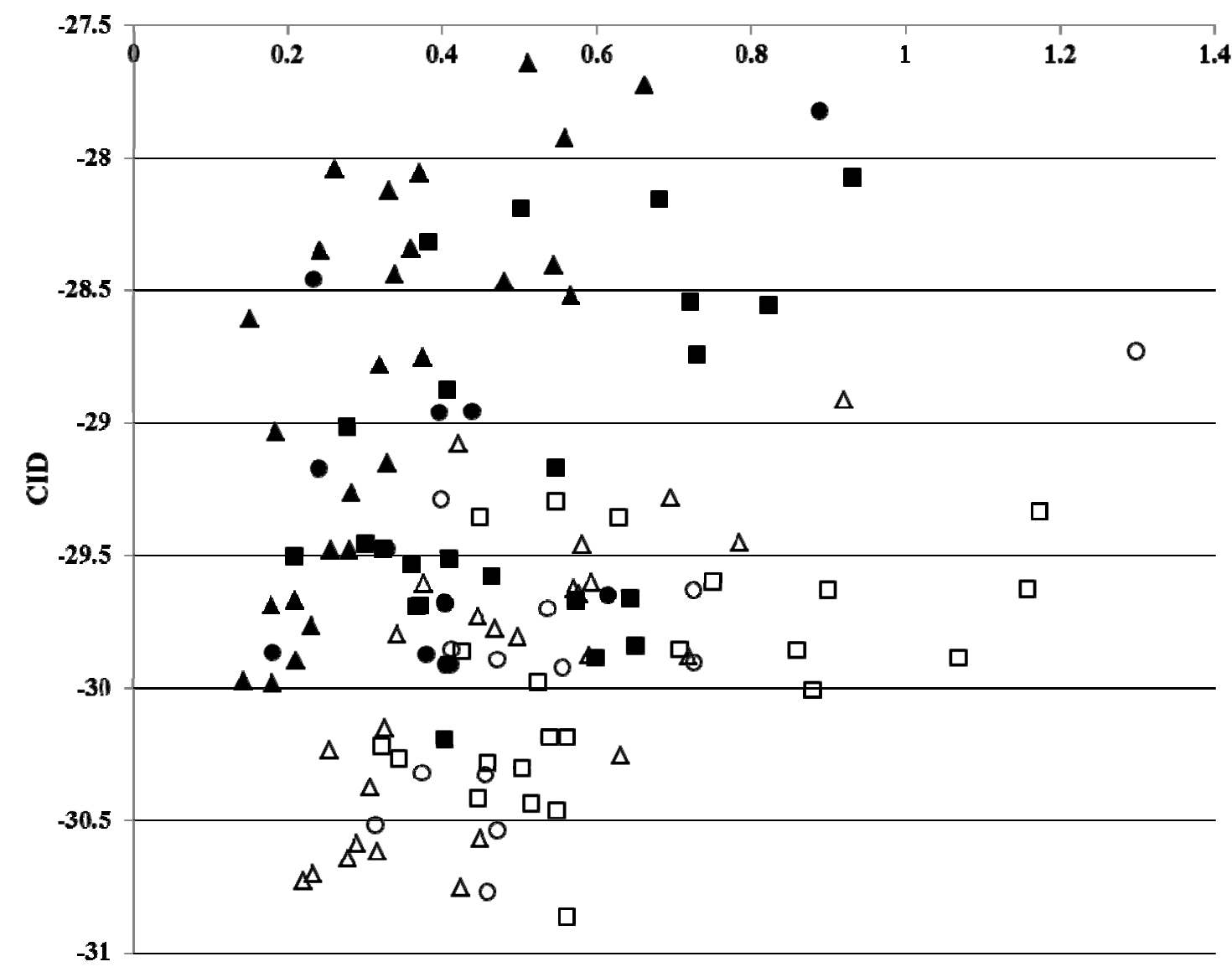

\section{Dry weight per plant (g)}

Fig. 4 Relationship between CID and shoot dry matter showing the clustering of untreated and treated samples. Each point represents the results for individual genotype samples, which is in turn labelled according to the tolerance to salt (susceptible: round symbol, moderate: triangle symbol and tolerant genotypes: square symbol) and to the group Control (open symbols), treated (solid symbols).

\section{Discussion}

Rice is a crop plant that is relatively susceptibility to salinity $[17,36]$, but genotypic differences are known at different growth stages [37]. The current work used a hydroponic system to study seedling response (the most susceptible growth stage) of 62 rice genotypes of varying tolerance to salt. Various growth parameters were measured in the initial experiments. The number of tillers was found to be of no value as an indicator of salt tolerance in rice at the seedling stage as all genotypes behaved the same in this respect, despite the fact that Nicolas et al. [38] reported in wheat that salinity may inhibit tiller formation and even tiller abortion during tiller emergence. Differences between standard genotypes were observed for plant height and shoot weight (fresh and dry) between treatments. $10 \mathrm{dS} / \mathrm{m} \mathrm{NaCl}$ salt affected rice seedling growth showing significant decreased of the shoot fresh and dry weight, plant height (Table 1 and Fig. 1). 'Pokkali' and 'Nona Bokra' are both tall genotypes whereas moderate and susceptible are semi-dwarfs. Tall types were therefore associated with salt tolerance; the height factor could be removed by calculating height reduction in salt stress as compared to control conditions for all genotypes. 'Pokkali' and 'Nona Bokra' were used in experiments by Banik et al. [39] who observed growth reduction after 21 days of $10 \mathrm{dS} / \mathrm{m}$ salt stress of $20 \%$ and $21 \%$ after 16 days, respectively. The salt tolerance of 'Pokkali' and 'Nona Bokra' has been reported 
independently by several workers [19, 40-43]. Our data corroborate these findings. More susceptible genotypes resulted in great reductions in plant height (Table 1, Fig. 1).

The 62 rice genotypes studied with known salt tolerance exhibited diversity with respect to plant vigour. Thus a range of plant heights were recorded: tall, semi-dwarf and dwarf. Each salt tolerant category classes within tall, semi-dwarf and dwarf genotypes while, tall and tolerant genotypes record similar performance as well as semi-dwarf or dwarf tolerant genotypes. The performance under salt is independent of the plant tallness. Thus, different performance was observed regarding the fresh and dry weight and plant height even after normalization which was not always in accordance with the reported salt tolerance.

Carbon isotope discrimination (CID) was generally effective in classifying salt tolerant and salt susceptible genotypes with tolerant genotypes having a tendency to maintain more negative $\delta^{13} \mathrm{C}$ values compared to the susceptible ones. CID has been used as an indirect screening method for selecting better and adapted cultivars to adverse environmental conditions such as drought, salt, etc. Many studies have used CID in selecting salt tolerance in rice [21-24, 44, 45]. Our CID data are in agreement with the salt tolerance of the standard lines and confirmed their classes as tolerant, moderately tolerant and susceptible. For more information on the use CID as a surrogate for salt tolerance, the reader is referred to recent publications [46-48]. Here we focus on the ability to screen for salt tolerance using element composition in non-stressed conditions.

Element analyses were carried out on 12 elements, but one objective was to streamline analyses to include only the most informative elements in developing a simplified salt tolerance analysis. Leaf samples were found to be more informative and easier to sample than roots. Combined analyses of shoots were performed on the elements with the greatest effects ( $\mathrm{Na}, \mathrm{Cl}, \mathrm{Mg}, \mathrm{K}$ and $\mathrm{P}$ ) in salt tolerance tests on the six standard genotypes (Table 3). This was not confined to total content of these elements in shoots, but also included informative ratios, such as $\mathrm{K}: \mathrm{Na}$, $\mathrm{Ca} N \mathrm{Na}, \mathrm{Mg}: \mathrm{Na}$ and $\mathrm{Na} \mathrm{Cl}$. These element ratios yielded the same discrimination between the rice genotypes as total elements in PCA and CDA analysis. $\mathrm{K}: \mathrm{Na}, \mathrm{Ca}: \mathrm{Na}$, and $\mathrm{Mg}: \mathrm{Na}$ were positively correlated with salt tolerance (Table 3). Increases in $\mathrm{Na}$ and $\mathrm{Cl}$ contents of shoots were associated with salt susceptibility, but the effect of $\mathrm{Cl}$ was weak, suggesting that $\mathrm{Na}$ is the main toxic element for all genotypes tested. However, damaging effects of $\mathrm{Cl}$ are observed with moderate and susceptible genotypes. The toxic effects of $\mathrm{Na}$ are well known and correlated with the grain yield under saline conditions [49-53], whereas there are few reports on toxic effects of $\mathrm{Cl}$ in salinity experiments $[3,9,33,54-58]$. For further information on the roles of $\mathrm{Na}$ and $\mathrm{Cl}$ in plants under salt stress see Teakle and Tyerman [59] and Flowers et al. [60].

Single or combined element ratios were scattered in the 62 rice genotypes under control and salt stress conditions within each salt category compared to the standards. The data are in agreement with the findings of Chunthaburee et al. [61] who used 12 rice cultivars including two of the standards used here, 'Pokkali' and 'IR29', in which $\mathrm{K} / \mathrm{Na}$ ratio was only able to discriminate salt tolerance under salt stress conditions. This demonstrates the complexity of mechanism involved in salt tolerance and the difficulty in identifying a single criteria, see also Ashraf [62] and, Shahbaz and Ashraf [63]. Our data show that salt treatment affects the composition of several elements. However, the loading of each element may differ from others because of its importance in various physiological systems, plant growth, regulations, etc. (Tables 4 and 5). In order to get a handle on these multiple effects, the fourteen elements detected and analysis by PIXE and XRF were combined by PCA and CDA. The resulting clustering of the genotypes into 3 classes provides evidence of genetic variation 
for salt tolerance in rice in respect to shoot accumulation and discrimination of elements (Figs. 2 and 3). Furthermore the same trend of clustering and differentiation was observed with element content under control and saline conditions (Figs. 2 and 3). This is a new and interesting finding. The contribution of different elements in the PCA show that shoot $\mathrm{Na}$, $\mathrm{Cl}, \mathrm{Mg}, \mathrm{K}$ and $\mathrm{P}$ concentrations exhibit big changes between treatments (Tables 4 and 5). The results obtained for the control samples revealed that tolerant genotypes have comparatively larger intakes of elements than moderate-tolerant and susceptible ones. Thus the ability to discriminate elements is important feature of salt tolerant genotypes [64]. The clustering in response to salt stress is independent of plant type (tall, semi-dwarf and dwarf) as these were found in each salt category. Thus the linkage between salt tolerance and height can be broken, an important point for plant breeders.

Screening for salt tolerance in control conditions presents many advantages for plant breeders. An initial non-destructive screen for salt tolerance may be carried out in benign, fertile conditions on young plants. Early generations may be tested and grown on to produce relatively large numbers of seed for subsequent field testing in saline conditions for confirmation. In addition that allows further screening for other interested traits. These findings may be applicable to other crops.

\section{Conclusions}

Salt tolerance in rice cultivars can be screened for in non-stressed conditions. This conclusion was formulated from a series of experiments in which the salt tolerance of six standards was confirmed using biomass data from hydroponic culture in saline and non-saline conditions. Element composition was determined by PIXE and XRF, which is a new application for these atomic spectroscopy techniques. Element composition data were able to discriminate between the six standard rice genotypes classed as tolerant, moderate or susceptible to salt (two in each class). Furthermore, the ranking of salt tolerance with respect to element composition was the same in salt and control treatments. These findings were validated by extending the study to a large range (62) of rice genotypes from various countries.

The concentration of elements in rice shoots can serve as a basis for predicting the response to salinity stress. The most effective measurements are shoot dried weight and elemental composition, particularly the ratio $\mathrm{Ka}: \mathrm{Na}$ and $\mathrm{Mg}: \mathrm{Na}$ under salt stress taken at 16 DAT. That may be assessed from leaf biopsies and plants possessing element compositions indicative of salt tolerance selected. Testing for salt tolerance in benign conditions offers a simple, non-destructive pre-screen for plant breeders and since the tests may be conducted in fertile areas large amounts of seed may be harvested for subsequent testing, e.g. in saline fields.

\section{Acknowledgement}

This work was funded by Food and Agriculture Organization of the United Nations and the International Atomic Energy Agency through their Joint FAO/IAEA Programme of Nuclear Techniques in Food and Agriculture. We would like to thank Berthold Guenter for its technical support, and Glenn Gregorioand Allan P. Salabsabin from International Rice Research Institute (IRRI, Philippines) for providing seed of the rice genotypes.

Author Contributions: S.B., B.P.F and M. L. designed research; S.B., A.M.A.G., S.N. and B.P.F. performed research; S.B., R.P-A., A.M., Y.D. and M.J. performed spectroscopy analysis; S.B and C.R. performed the CID analysis. S.B., B.P.F. and M.L. wrote the paper.

The authors declare no conflict of interest.

\section{References}

[1] Rengasamy, P. 2010. "Soil Processes Affecting Crop Production in Salt-Affected Soils." Funct. Plant Biol. 37: 613-20. 
[2] Islam, M. S., Rahman, M. A., Sultana, N., Nath, B. and Paul, A. 2012. "Using Geospatial Techniques to Assess the Salinity Impact on Agricultural Landuse: a Study on Shyamnagar Upazila, Satkhira.” JAEID 106 (2): 157-69.

[3] Munns, R., James, R. A., Xu, B., Athman, A., Conn, S. J. and Jordans, C. et al. 2012. "Wheat Grain Yield on Saline Soils is Improved by an Ancestral $\mathrm{Na}^{+}$Transporter Gene." Nat Biotechnol 30: 360-4.

[4] Horie, T., Karahara, I. and Katsuhara, M. 2012. "Salinity Tolerance Mechanisms in Glycophytes: An Overview with the Central Focus on Rice Plants." Rice 5: 11-28.

[5] Flowers, T. J. and Flowers, S. A. 2005. "Why Does Salinity Pose Such a Difficult Problem for Plant Breeders?" Agr Water Manage 78: 15-24.

[6] Mansour, M. M. F., Salama, K. H. A., Ali, F. Z. M. and Hadid, A. F. A. 2005. "Cell and Plant Responses to $\mathrm{NaCl}$ in Zea mays L. Cultivars Differing in Salt Tolerance." Gen Appl. Plant Physiol. 31: 29-41.

[7] Munns, R. and Tester, M. 2008. "Mechanisms of Salinity Tolerance.” Annu Rev Plant Biol. 59: 651-81.

[8] Munns, R., Husain, S., Rivelli, A. R., James, R. A, Condon, A. G. and Lindsay, M. P. et al. 2002. "Avenues for Increasing Salt Tolerance of Crops, and the Role of Physiologically Based Selection Traits." Plant and Soil 247: 93-105.

[9] Munns, R. 2002. "Comparative Physiology of Salt and Water Stress." Plant Cell and Environment 25: 239-50.

[10] Andeden, E. E., Yediay, F. E., Baloch, F. S., Shaaf, S., Kilian, B., Nachit, M. M. and Zkan, H. 2011. "Distribution of Vernalization and Photoperiod Genes (Vrn-A1, Vrn-B1, Vrn-D1, Vrn-B3, Ppd-D1) in Turkish Bread Wheat Cultivars and Landraces." Cereal Res Commun. 39: 352-64.

[11] Eagles, H. A., Cane, K., Trevaskis, B., Vallance, N., Eastwood, R. F. and Gororo, N. N. et al. 2014. "Ppd1, Vrn1, ALMT1 and Rht Genes and Their Effects on Grain Yield in Lower Rainfall Environments in Southern Australia." Crop Pasture Sci. 65: 159-70.

[12] Kiss, T., Balla, K., Veisz, O., Láng, L., Bedő, Z. and Griffiths, S. et al. 2014. "Allele Frequencies in the VRN-A1, VRN-B1 and VRN-D1 Vernalization Response and PPD-B1 and PPD-D1 Photoperiod Sensitivity Genes, and Their Effects on Heading in a Diverse Set of Wheat Cultivars (Triticum aestivum L.)." Mol Breed 34 (2): 297-310.

[13] Sankar, P. D., Maam, S. and Selvaraj, C. I. 2011. "Rice Breeding for Salt Tolerance.” Res Biotechnol 2 (2): 1-10.

[14] Todaka, D., Nakashima, K., Shinozaki, K. and Yamaguchi-Shinozaki, K. 2012. "Toward Understanding Transcriptional Regulatory Networks in Abiotic Stress Responses and Tolerance in Rice." Rice 5: 6-14.

[15] Fairhurst, T. H. and Doberman, A. 2002. "Rice in the
Global Food Supply." Better Crop International 16: 3.

[16] Shannon, M. C., Rhoades, J. D., Draper, J. H., Scardaci, S. C. and Spyres, M. D. 1998. "Assessment of Salt Tolerance in Rice Cultivars in Response to Salinity Problem in California." Crop Sci. 38 (2): 394-8.

[17] Roy, S. J., Tucker, E. J. and Tester, M. 2011. "Genetic Analysis of Abiotic Stress Tolerance in Crops." Curr Opin Plant Biol 14: 232-9.

[18] Gregorio, G. B., Senadhira, D. and Mendoza, R. T. 1997. "Screening Rice for Salinity Tolerance." IRRI Discussion Paper Ser 22. Manila.

[19] Afza, R., Zapata-Arias, F. J., Zwiletitsch, F., Berthold, G. and Gregorio, G. 1999. "Modification of a Rapid Screening Method of Rice Mutants for $\mathrm{NaCl}$ Tolerance Using Liquid Culture." Mutat Breed Newsl 44: 25-28.

[20] Yoshida, S., Forno, D. A., Cock, J. H. and Gomez, K. A. 1976. "Laboratory Manual for Physiological Studies of Rice.” Las Banos, Laguna: IRRI, 83.

[21] Shaheen, R. and Hood-Nowotny, R. C. 2005. "Carbon Isotope Discrimination: Potential for Screening Salinity Tolerance in Rice at the Seedling Stage Using Hydroponics." Plant Breed 124: 220-4.

[22] Dadkhah, A. and Ghorbanzadeh-Neghab, M. 2012. "Carbon Isotope Discrimination, A Tool for Screening of Salinity Tolerance of Genotypes. International Scholarly and Scientific Research \& Innovation 6 (9): 121-4.

[23] Brugnoli, E. and Lauteri, M. 1991. "Effects of Salinity on Stomatal Conductance, Photosynthetic Capacity, and Carbon Isotope Discrimination of Salt-Tolerant (Gossypium hirsutum L.) and Salt-Sensitive (Phaseolus vulgaris L.) C (3) Non-Halophytes." Plant Physiol 95 (2): 628-35.

[24] Shaheen, R. and Hood-Nowotny, R. C. 2004. "Effect of Drought and Salinity on Carbon Isotope Discrimination in Wheat Cultivars." Plant Sci 168: 901-9.

[25] Padilla, R., van Espen, P. and Torres, P. P. G. 2006. "The Suitability of XRF Analysis for Compositional Classification of Archaeological Ceramic Fabric: a Comparison with a Previous NAA Study." Anal Chim Acta 558: 283-9.

[26] Bado S., Padilla-Alvarez R., Migliori A., Forster B.P., Jaksic M., Diawara Y., Kaiser R.B. and Laimer M. 2016. "The Application of XRF and PIXE in the Analysis of Rice Shoot and Compositional Screening of Genotypes." Nuclear Instruments and Methods in Physics Research Section B: Beam Interactions with Materials and Atoms, 371: 407-12. http://dx.doi.org/10.1016/j.nimb.2015.08.081.

[27] Tal, M. 1985. "Genetics of Salt Tolerance in Higher Plants: Theoretical and Practical Considerations." Plant and Soil 89: 199-226.

[28] Dasgan, H. Y., Aktas, H., Abak, K. and Cakmak, I. 2002. 


\section{Content under Non-Stressed Conditions}

"Determination of Screening Technique to Salinity Tolerance in Tomatoes and Investigation of Genotypes Responses." Plant Sci. 163: 695-703.

[29] Hussain, N., Ali, A., Khan, A. G., Rehman, O-U. and Tahir, M. 2003. "Selectivity of Ions Absorption as Mechanism of Salt Tolerance in Rice [variety Shaheen Basmati]." Asian J Plant Sci. 2: 445-8.

[30] Flowers, T. J. 2004. "Improving Crop Salt Tolerance." $J$ Exp Bot 55: 307-19.

[31] Moradi, F. and Ismail, A. M. 2007 "Responses of Photosynthesis, Chlorophyll Fluorescence and ROS-Scavenging Systems to Salt Stress during Seedling and Reproductive Stages in Rice." Ann Bot 99: 1161-73.

[32] Saleh, B. 2011. "Effect of Salt Stress $(\mathrm{NaCl})$ on Biomass and $\mathrm{K}^{+} / \mathrm{Na}^{+}$Ratio in Cotton." J stress Physiol Biochem. 7 (4): 5-14.

[33] Saleh, B. 2011. "Ion Partitioning and $\mathrm{Mg}^{2+} / \mathrm{Na}^{+}$Ratio under Salt Stress Application in Cotton." J Stress Physiol Biochem 7 (4): 292-300.

[34] Mardia, K. V., Kent, J. T. and Bibbly, J. M. 1979. "Multivariate Analysis." London: Academic Press Inc.

[35] Johnson, R. A. and Wichern, D. W. 2007. "Applied multivariate statistical analysis.” Sixth Eds. Prentice-Hall, Englewood Cliffs, USA.

[36] Kavitha, P. G., Miller, A. J., Mathew, M. K. and Maathuis, F. J. M. 2012. "Rice Cultivars with Differing Salt Tolerance Contain Similar Cation Channels in Their Root Cells." J Exp Bot 63 (8): 3289-96.

[37] Zeng, L., Shannon, M. C. and Grieve, C. M. 2002. "Evaluation of Salt Tolerance in Rice Genotypes by Multiple Agronomic Parameters." Euphytica 127: 235-45.

[38] Nicolas, M. E., Munns, R., Samarakoon, A. B., Gifford, R. M. 1994. "Elevated $\mathrm{CO}_{2}$ Improves the Growth of Wheat under Salinity." Aust J Plant Physiol 20: 349-60.

[39] Banik, M., Karim, N. H. and Haque, M. Z. 1994."Salinity Tolerance of Rice as Related to Growth and Physiological Characteristics. Ann Bangladesh Agric 4: 41-6.

[40] Flowers, T. J. and Yeo, A. R. 1981. "Variability in the Resistance of Sodium Chloride Salinity within Rice [Oryza sativa L.] Varieties.” New Phytol 88: 363-73.

[41] Akita, S. and Cabuslay, G. S. 1990. "Physiological Basis of Differential Response to Salinity in Rice." Plant and Soil 123: 277-94.

[42] Yeo, A. R., Yeo, M. E. and Flowers, T. J. 1990. "Screening of Rice [Oryza sativa L.] Genotypes for Physiological Characters Contributing to Salinity Resistance, and Their Relationship to Overall Performance." Theor Appl Genet 79: 377-84.

[43] Dionisio-Sese, M. L. and Tobita, S. 1998. "Antioxidant Responses of Rice Seedlings to Salinity Stress.” Plant Sci.
135: 1-9.

[44] Islam, M. M., Begum, S. N., Emon, R. M., Halder, J. and Manidas, A. C. 2011. "Carbon Isotope Discrimination in Rice under Salt Affected Conditions in Bangladesh". In Greater Agronomic Water Use Efficiency in Wheat and Rice Using Carbon Isotope Discrimination. IAEA-TECDOC-1671, 7-23.

[45] Ismail, A. M., Katimbang, M. L., Egdane, J. A. and Thomson, M. J. 2011. "Carbon Isotope Discrimination and Salt Tolerance in Rice." In Greater Agronomic Water Use Efficiency in Wheat and Rice Using Carbon Isotope Discrimination. IAEA-TECDOC-1671, 49-66.

[46] Cui, Y. Q., Ma, J. Y. and Sun, W. 2011. "Application of Stable Isotope Techniques to the Study of Soil Salinization." J Arid Land 3 (4): 285-91.

[47] Dadkhah, A. 2013. "Effect of Salinity on Carbon Isotope Discrimination of Shoot and Root of Four Sugar Beet (Beta vulgaris L.) Cultivars." J Agric Sci. Technol (15): 901-10.

[48] Ivlev, A. A., Pichouzkin, V. I., Tarakanov, I. G. 2013. "Soil Salinity Effect on Carbon Isotope Composition of Plant Biomass." Adv St Biol 5 (5): 223-34.

[49] Maathuis, F. J. M. and Amtmann, A. 1999. " $\mathrm{K}^{+}$Nutrition and $\mathrm{Na}^{+}$Toxicity: The Basis of Cellular $\mathrm{K}^{+} / \mathrm{Na}^{+}$Ratios." Ann. Bot 84: 123-33.

[50] Zeng, L., Poss, J. A., Wilson, C., Draz, A. E., Gregorio, G. B. and Grieve, C. M. 2003. "Evaluation of Salt Tolerance in Rice Genotypes by Physiological Characters." Euphytica 129: 281-92.

[51] Shereen, A., Ansari, R. U., Yasmin, S., Raza, S., Mumtaz, S., Khan, M. A. and Mujtaba, S. M. 2007. "Physiological Responses of Rice [Oryza sativa L.] to Saline Stress." Pak J Bot 39 (7): 2527-34.

[52] Khan, M. A., Shirazi, M. U., Khan, M. A., Mujtaba, S. M., Islam, E. and Mumtaz, S. et al. 2009. "Role of Proline, K/Na Ratio and Chlorophyll Content in Salt Tolerance of Wheat [Triticum aestivum L.]." Pak J Bot 41: 633-8.

[53] Zhang, J.-L., Flowers, T. J. and Wang, S.-M. 2009. "Mechanisms of Sodium Uptake by Roots of Higher Plants." Plant Soil 326: 45-60.

[54] Ashraf, M. and McNeilly, T. 1987. "Salinity Effects on Five Cultivars/Lines of Pearl Millet (Pennisetum americanum [L] Leeke)." Plant and Soil 103: 13-9.

[55] Sharma, S. K. 1996. "Effects of Salinity on Uptake and Distribution of $\mathrm{Na}^{+}, \mathrm{Cl}^{-}$and $\mathrm{K}^{+}$in Two Wheat Cultivars." Biol Plantarum 38 (2): 261-7.

[56] Chartzoulakis, K., Loupassaki, M., Bertaki, M. and Androulakis, I. 2002. "Effect of $\mathrm{NaCl}$ Salinity on Growth, Ion Content and $\mathrm{CO}_{2}$ Assimilation Rate of Six Olive Cultivars." Scientia Horticulturae 96: 235-47.

[57] Akhtar, J., Saqib, Z. A., Saleem, I. and Haq, M. A. 2010. 


\section{Content under Non-Stressed Conditions}

"Evaluating Salt Tolerance Cotton Genotypes at Different Levels of $\mathrm{NaCl}$ Stress in Solution and Soil Culture." Pak $J$ Bot 42: 2857-66.

[58] Keutgen, A. J. and Pawelzik, E. 2009. "Impacts of $\mathrm{NaCl}$ Stress on Plant Growth and Mineral Nutrient Assimilation in Two Cultivars of Strawberry." Environ Exp Bot 65: 170-6.

[59] Teakle, N. L. and Tyerman, S. D. 2010. "Mechanisms of $\mathrm{Cl}^{-}$Transport Contributing to Salt Tolerance." Plant Cell and Environ 33: 566-89.

[60] Flowers, T. J., Munns, R. and Colmer, T. D. 2014. "Sodium Chloride Toxicity and the Cellular Basis of Salt Tolerance in Halophytes." Ann Bot 115 (3): 327-31.
[61] Chunthaburee, S., Dongsansuk, A., Sanitchon, J., Pattanagul, W. and Theerakulpisut, P. 2015. "Physiological and Biochemical Parameters for Evaluation and Clustering of Rice Cultivars Differing in Salt at Seedling Stage. Saudi J Biol Sci.

[62] Ashraf, M. 2004. "Some Important Physiological Selection Criteria for Salt Tolerance in Plants." Flora 199: 361-76.

[63] Shahbaz, M. and Ashraf, M. 2013. "Improving Salinity Tolerance in Cereals." Crit Rev Plant Sci. 32 (4): 237-49.

[64] Zeng, L. 2005. "Exploration of Relationship between Physiological Parameters and Growth Performance of Rice [Oryza sativa L.]." Plant and Soil 268: 51-9. 